\title{
ON THE REALIZATION OF LOW/HIGH FREQUENCY CCII+ BASED OSCILLATORS EMPLOYING GROUNDED RESISTORS AND LOSSY CAPACITORS
}

\author{
MUHAMMAD TAHER ABUELMA'ATTI AND MUHAMMAD \\ HAROON KHAN
}

King Fahd University of Petroleum and Minerals, Box 203, Dhahran 31261, Saudi Arabia

(Received August 16, 1994; in final form September 7, 1994)

\begin{abstract}
New RC oscillator circuits are presented. Each circuit uses two second-generation positive currentconveyors, three grounded capacitors and four grounded resistors. The circuits enjoy independent control of the frequency and the condition of oscillation and are very attractive for integration. The circuits can realize high and low frequencies of oscillation. Simulation results are included.
\end{abstract}

\section{INTRODUCTION}

Recently, Chang ${ }^{1}$ proposed a current-conveyor-based voltage-controlled oscillator (VCO). The circuit has the following major advantageous features: independent frequency and oscillation control and employment of grounded resistors and capacitors. The circuit, however, has the following disadvantageous features: use of three different current-conveyors, and the need to use a high quality capacitor as no resistor is used in parallel with one of the capacitors. Moreover, the circuit is unable to generate low frequencies without using large values of capacitors and/ or resistors. This is because no difference term is involved in the expression for the frequency of oscillation.

The purpose of this paper is, therefore, to present new current-conveyor-based oscillator circuits. Each circuit enjoys the following features:

1. Utilizes two positive second-generation current-conveyors (CCII+).

2. Uses grounded lossy capacitors and resistors.

3. Independent frequency and oscillation control.

4. Usable for high and low frequency generation.

\section{PROPOSED CIRCUIT}

Consider the oscillator circuit structure shown in Fig. 1. Assuming ideal CCII+ with $\mathrm{i}_{\mathrm{x}}=\mathrm{i}_{\mathrm{z}}, \mathrm{i}_{\mathrm{y}}=0, \mathrm{v}_{\mathrm{x}}=\mathrm{v}_{\mathrm{y}}$, routine analysis shows that the characteristic equation of the circuit can be expressed as 


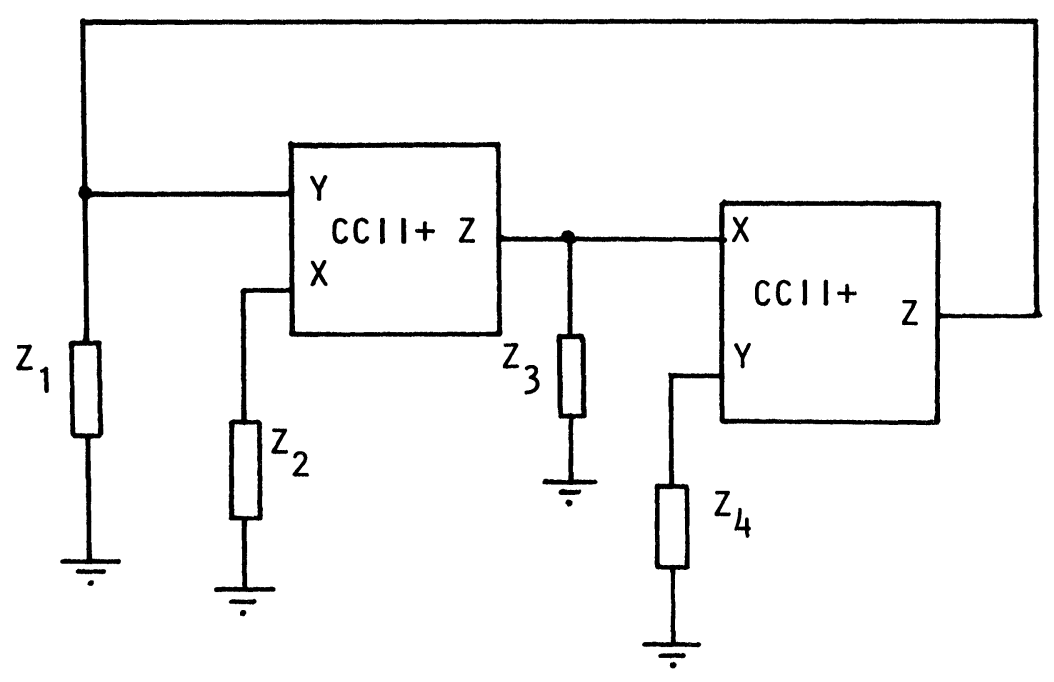

FIGURE 1 Proposed oscillator structure.

$\mathrm{Z}_{1} \mathrm{Z}_{3}-\mathrm{Z}_{2} \mathrm{Z}_{4}=0$

Using (1), many oscillator circuits can be derived. Here we will consider only oscillator circuits with lossy capacitors, that is, with each capacitor connected in parallel with a resistor. The resulting four oscillator circuits are shown in Fig. 2 with their frequency and condition of oscillation tabulated in Table I.

From Table I, one can see that for each circuit, the frequency of oscillation can be adjusted by tuning one element without disturbing the condition of oscillation while the condition of oscillation can be adjusted by tuning another element without disturbing the frequency of oscillation. Thus, the circuits enjoy independent frequency and oscillation control. For example, for the circuit of Fig. 2(a), the frequency of oscillation can be adjusted by tuning the resistor $R_{3}$ without disturbing the condition of oscillation, while the condition of oscillation can be adjusted by tuning the capacitor $\mathrm{C}_{3}$ without disturbing the condition of oscillation. Moreover, one can also see from Table I that the frequency of oscillation contains a difference term. Thus, low frequencies of oscillation can be obtained without using large values of capacitors and/or resistors.

\section{SIMULATION RESULTS}

The proposed circuits were simulated using PSpice Student Version 5.0. Although there are several ways to simulate the current-conveyors required, the simulation was performed using the circuit proposed by Senani ${ }^{2}$ because of its simplicity. The kernel of the work presented in this paper is independent of the particular simulation selected. The CCII+ was simulated using one operational amplifier, one 

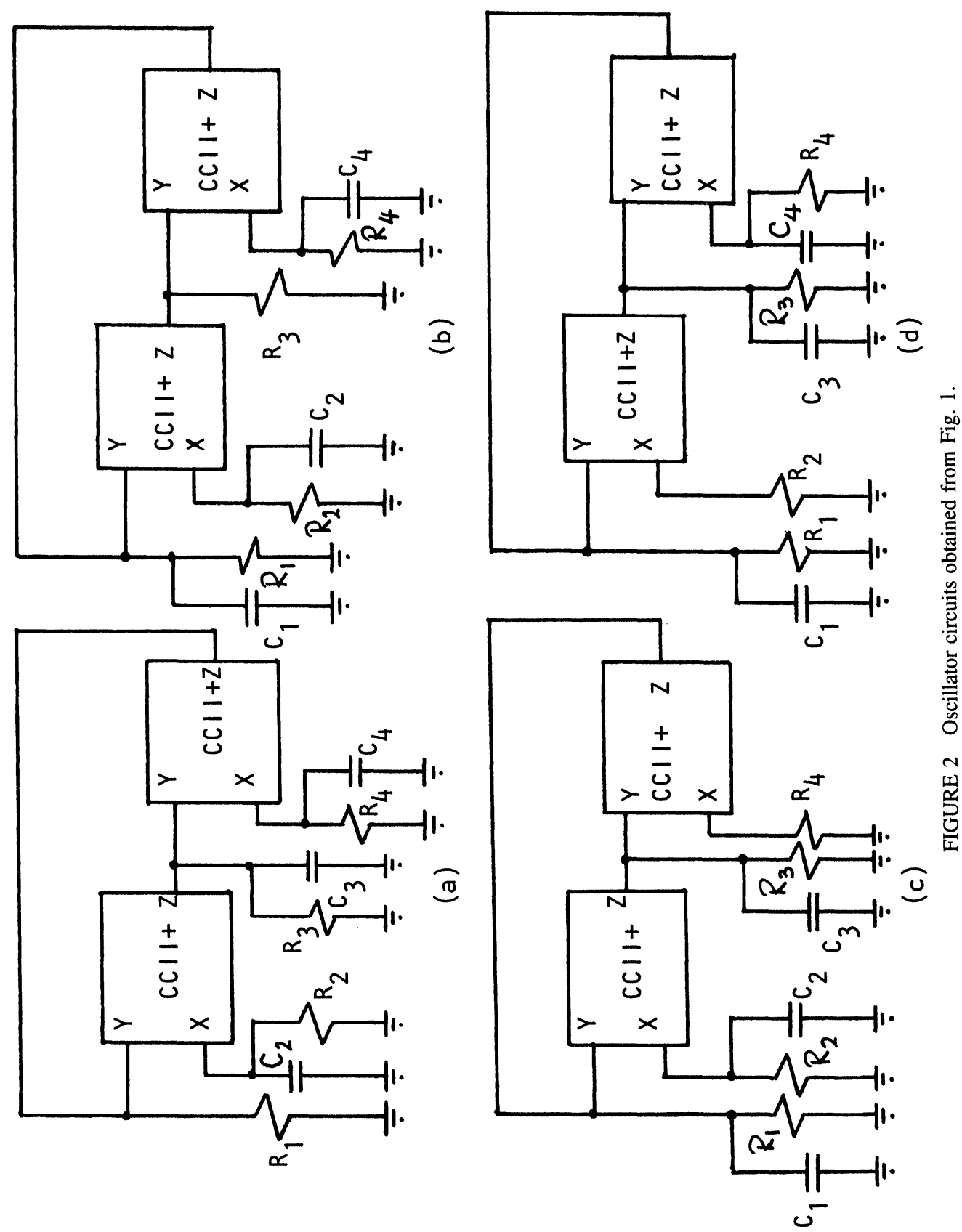
TABLE I

Frequency and condition of oscillation of the proposed circuits of Fig. 2

\begin{tabular}{|c|c|c|}
\hline Circuit & $\begin{array}{l}\text { Frequency of oscillation } \\
\omega_{0}^{2}\end{array}$ & Condition of oscillation \\
\hline a & $\frac{R_{1} R_{3}-R_{2} R_{4}}{R_{1} R_{2} R_{3} R_{4} C_{2} C_{4}}$ & $\mathrm{C}_{3} \mathrm{R}_{2} \mathrm{R}_{4}=\mathrm{R}_{1}\left(\mathrm{C}_{2} \mathrm{R}_{2}+\mathrm{C}_{4} \mathrm{R}_{4}\right)$ \\
\hline b & $\frac{R_{1} R_{3}-R_{2} R_{4}}{R_{1} R_{2} R_{3} R_{4} C_{2} C_{4}}$ & $\mathrm{R}_{2} \mathrm{R}_{4} \mathrm{C}_{1}=\mathrm{R}_{3}\left(\mathrm{R}_{2} \mathrm{C}_{2}+\mathrm{R}_{4} \mathrm{C}_{4}\right)$ \\
\hline c & $\frac{R_{2} R_{4}-R_{1} R_{3}}{R_{1} R_{2} R_{3} R_{4} C_{1} C_{3}}$ & $\mathrm{R}_{1} \mathrm{R}_{3} \mathrm{C}_{2}=\mathrm{R}_{4}\left(\mathrm{R}_{1} \mathrm{C}_{1}+\mathrm{R}_{3} \mathrm{C}_{3}\right)$ \\
\hline d & $\frac{R_{2} R_{4}-R_{1} R_{3}}{R_{1} R_{2} R_{3} R_{4} C_{1} C_{3}}$ & $R_{1} R_{3} C_{4}=R_{2}\left(R_{1} C_{1}+R_{3} C_{3}\right)$ \\
\hline
\end{tabular}

operational transconductance amplifier, and one resistor, shown in Fig. 3. The operational amplifier was simulated using the uA741 model contained in the file called EVAL.LIB available in the PSpice student version. The start of oscillation was caused by the offset voltage of the operational amplifier. ${ }^{3}$ To demonstrate that the oscillations were self starting, the voltages across the capacitors were initialized at zero values. The operational transconductance amplifier was simulated assuming a finite input resistance of $2 \mathrm{MOhm}$. To avoid the possible latch-up resulting from the non-zero offset current at terminal $\mathrm{Z}$ of the current-conveyors, an antiparallel diode pair was connected between terminal $\mathrm{Z}$ and the ground. Figure 4 shows the simulated oscillation obtained from the circuit of Fig. 2(a) with

$\mathrm{C}_{2}=\mathrm{C}_{4}=0.01 \mathrm{uF}, \mathrm{C}_{3}=0.02 \mathrm{uF}, \mathrm{R}_{1}=\mathrm{R}_{2}=\mathrm{R}_{4}=1.2 \mathrm{~K}, \mathrm{R}_{3}=2 \mathrm{~K}$

The simulation results appear to be in good agreement with the presented theory.

\section{CONCLUSION}

In this paper, four novel current-conveyor-based oscillator circuits have been pre-

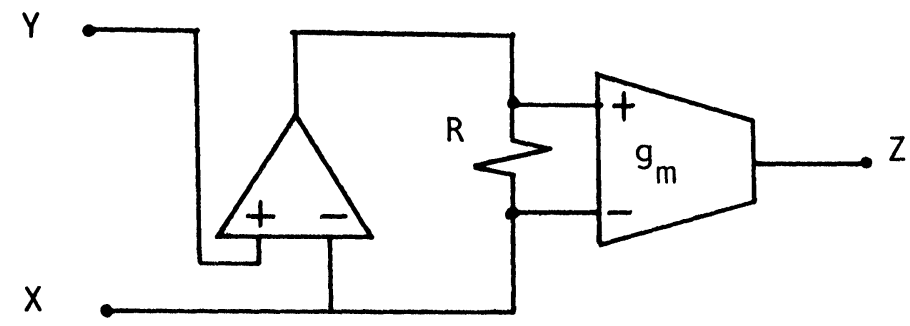

FIGURE 3 The CCII + realization proposed by Senani [2]. 


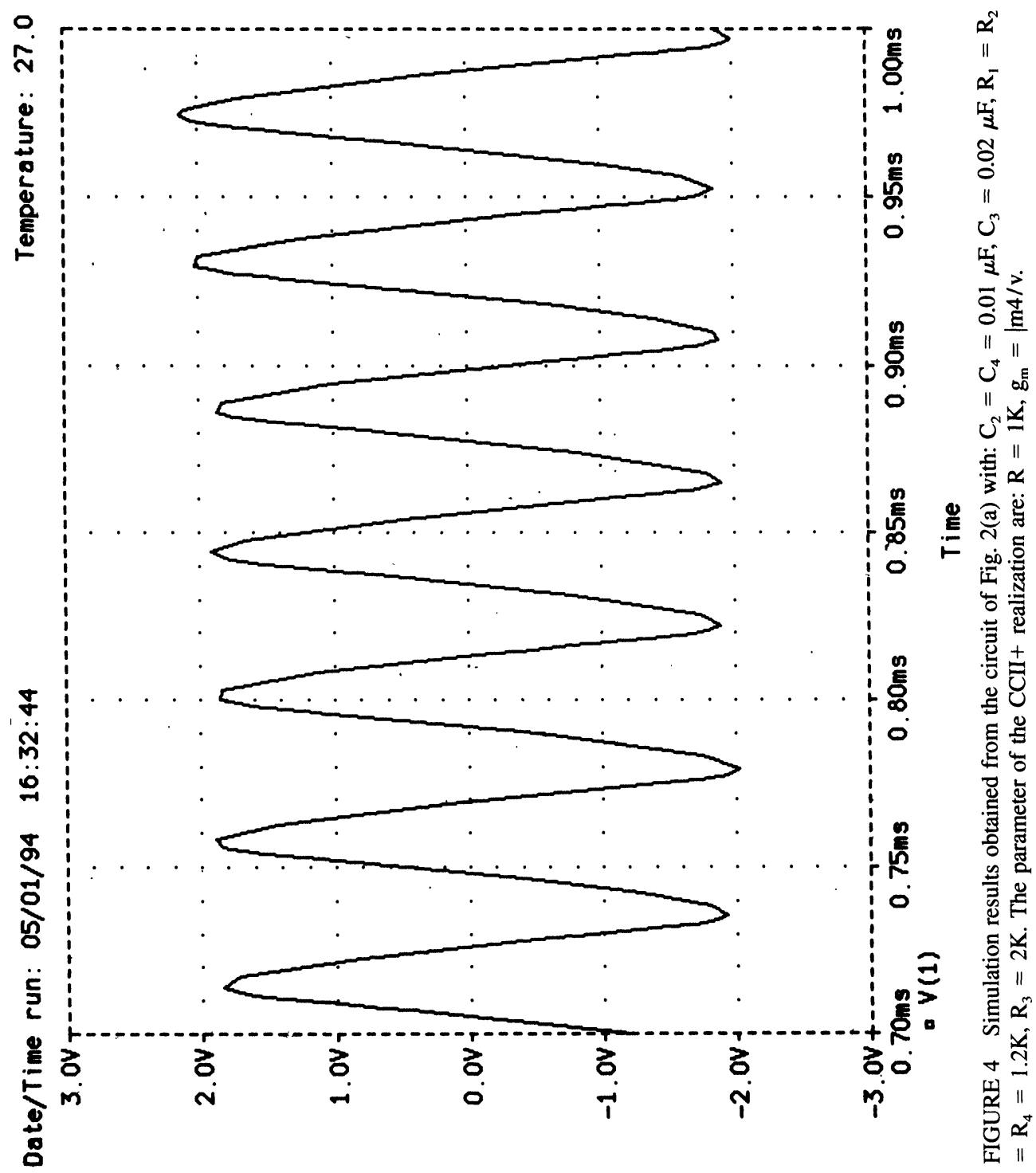


sented. Each circuit uses two positive second-generation current-conveyors, three grounded capacitors, and four grounded resistors. In all the circuits, each capacitor is connected in parallel with a resistor. Thus, lossy capacitors can be used. In all the circuits, the frequency of oscillation contains a difference term. Thus the realization of low frequencies of oscillation without using large values of resistors and/or capacitors is feasible. In all the circuits, the frequency of oscillation can be adjusted without disturbing the condition of oscillation and the condition of oscillation can be adjusted without disturbing the frequency of oscillation. Thus, the circuits enjoy independent frequency and oscillation control. Finally, some of the circuits, where the frequency of oscillation can be adjusted via a grounded resistor, can be easily converted to voltage-controlled oscillators simply by replacing the control resistor by a JFET. Thus, the realization of voltage controlled oscillators is practically feasible using two CCII + , grounded lossy capacitors, and resistors.

\section{REFERENCES}

[1] C.-M. Chang, Novel current-conveyor-based single-resistance-controlled/voltage-controlled oscillator employing grounded resistors and capacitors, Electronics Letters, Vol. 30, 1994, pp. 181-183.

[2] R. Senani, Novel circuit implementation of current conveyors using O.A. and an O.T.A., Electronics Letters, Vol. 16, 1980, pp. 203.

[3] G.W. Roberts and A.S. Sedra, SPICE for Microelectronics, 1992, Saunders College Publishing. 

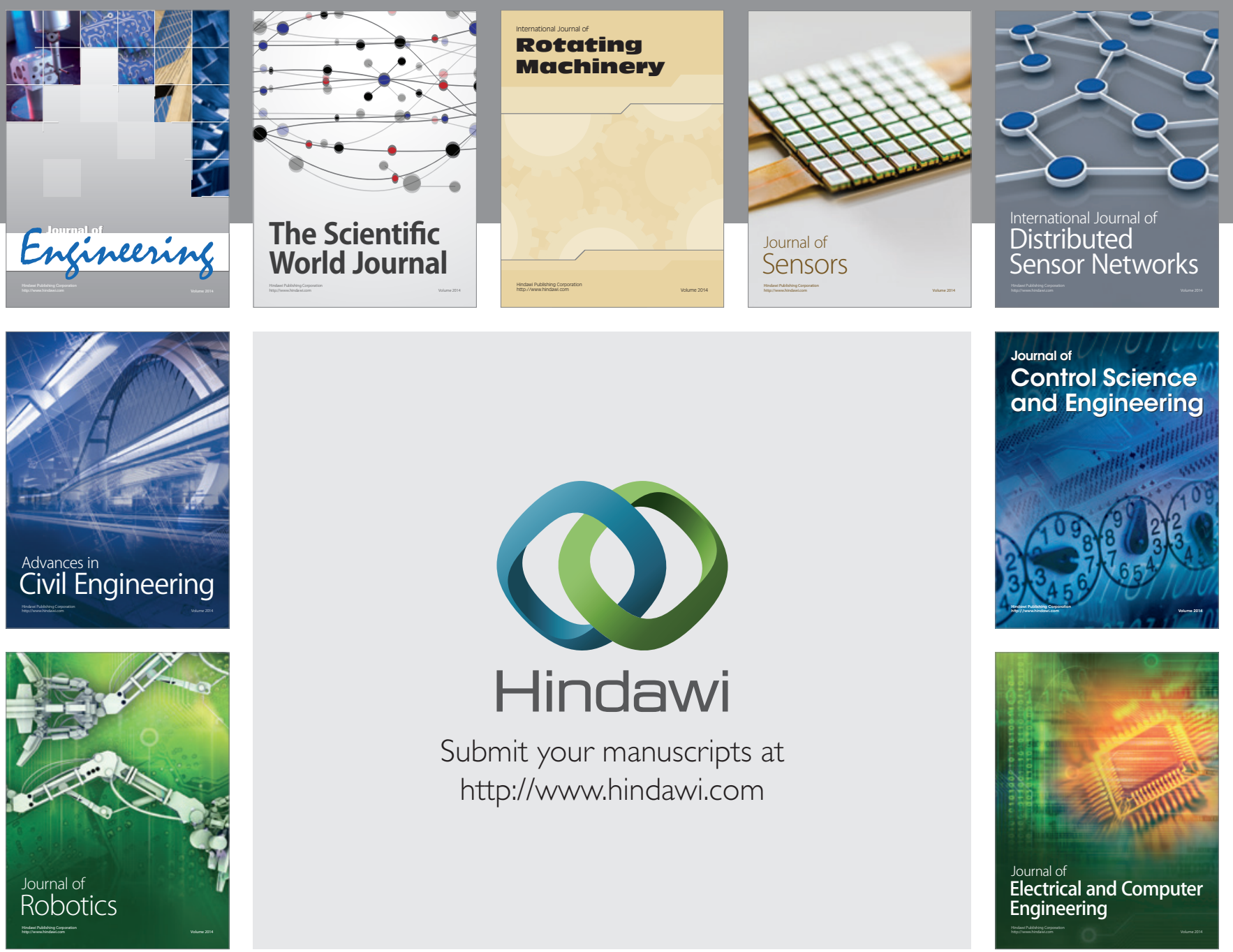

Submit your manuscripts at

http://www.hindawi.com
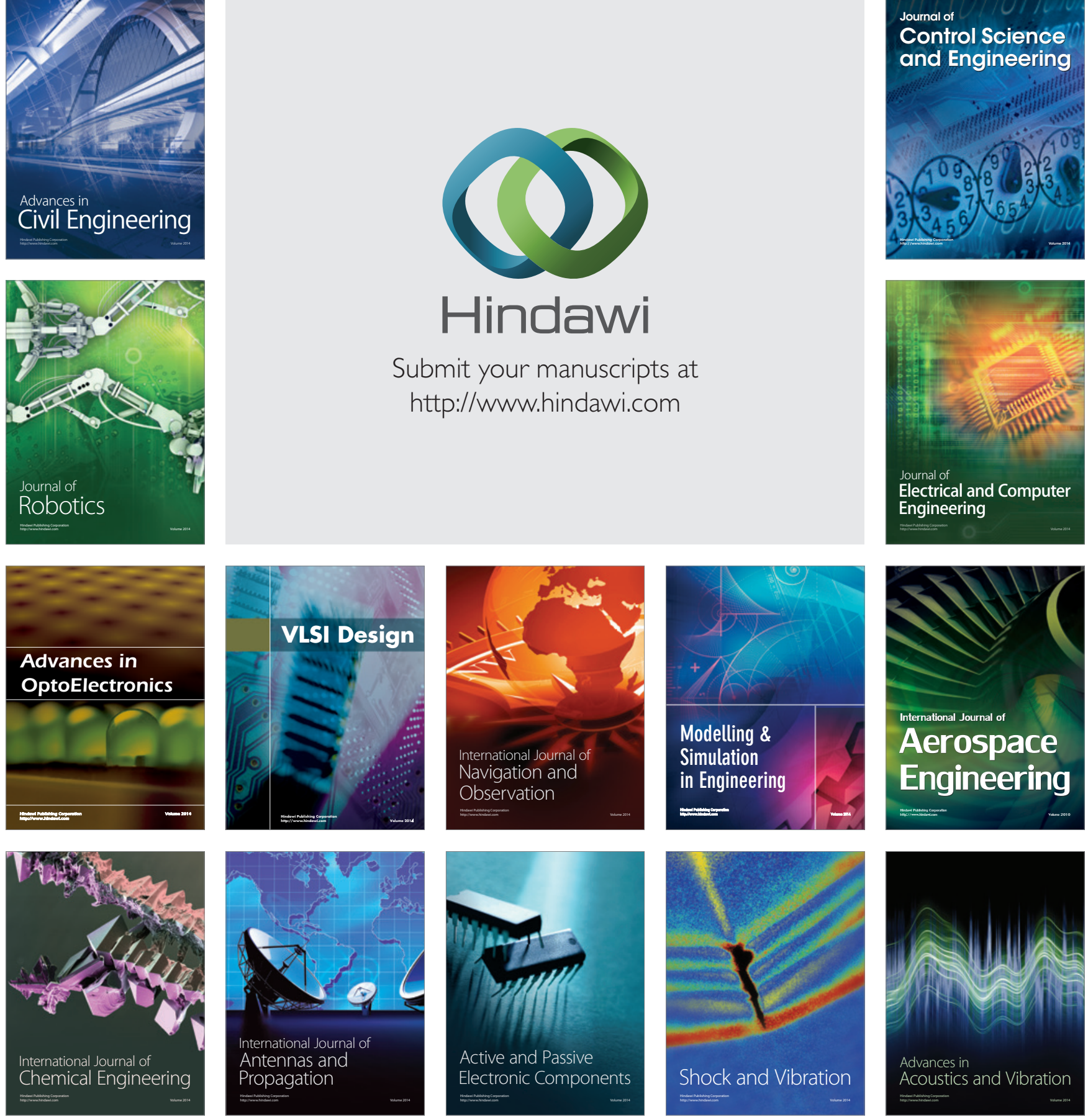